\title{
Medium-term recruitment patterns in Scottish freshwater pearl mussel Margaritifera margaritifera populations
}

\author{
L. C. Hastie*, E. C. Tarr, B. al-Mousawi, M. R. Young \\ Department of Zoology, University of Aberdeen, Tillydrone Avenue, Aberdeen AB24 2TZ, UK
}

\begin{abstract}
An investigation of recruitment levels in Scottish freshwater pearl mussel Margaritifera margaritifera (L.) populations was conducted in order to determine their medium-term viability. These mussels represent surviving populations considered to be currently viable (in that some recruitment had occurred during the past decade). Selected mussel beds in 8 rivers were surveyed at $\sim 10 \mathrm{yr}$ intervals between 1984 and 2007. Observed changes in mussel density (1996-2007) ranged from -50 to $+55 \%$. These may be due to the effects of pearl fishing activity, sampling bias, and, to a lesser extent, habitat degradation. Marked differences between size distributions and corresponding age distributions were observed. Large mussels ( $>50 \mathrm{~mm}$ shell length $L$ ) were predominant at every site, although evidence of recent recruitment (mussels $<30 \mathrm{~mm} L$ and/or aged $<5 \mathrm{yr}$ ) was observed in each population. Based on the relative abundance of juvenile mussels observed, medium-term stability is indicated in 4 populations. One large population appeared to have localised recruitment problems, as relatively few juveniles were found at one site but larger numbers were found in other parts of the river. Three smaller populations had very few juveniles and appeared to be recruiting at historically low levels. Continued monitoring of these sites every decade will provide valuable information about the population dynamics of long-lived freshwater mussels.
\end{abstract}

KEY WORDS: Population trends · Dynamics $\cdot$ Mussel beds $\cdot$ Margaritifera margaritifera

\section{INTRODUCTION}

During the past $100 \mathrm{yr}$, the freshwater pearl mussel Margaritifera margaritifera (L.) has declined throughout its holarctic range to the extent that it is now listed as an endangered species (IUCN 1991). The main causes are considered to be gross industrial and agricultural (organic) pollution, over-exploitation by pearl fishermen, decline of salmonid host stocks, and physical riverbed habitat degradation due to hydroelectric operations and river management schemes (Cosgrove et al. 2000). A number of Scottish rivers continue to support large M. margaritifera populations. These appear to exhibit short-term stability and are at least partly functioning (in that juvenile mussels have recently been found in them; Hastie et al. 2000a). The relatively large numbers of juveniles recorded in cer- tain rivers suggest that they are among the healthiest, least-stressed pearl mussel populations in western Europe (Young et al. 2001a). However, it is apparent that even in these populations, the expected predominance of young mussels has not been achieved (Hastie et al. 2000a). One would expect the numbers aged 1 to $10 \mathrm{yr}$ to be greater than those of older age classes (even if annual recruitment varied considerably). Across the geographic range of $M$. margaritifera, lower-thanexpected numbers of juveniles in populations have been reported consistently (Hendelberg 1961, Stober 1972, Ross 1982, Bauer 1983, 1986, al-Mousawi 1991, Moog et al. 1993, Ziuganov et al. 1994, Mackie \& Roberts 1992, Hastie et al. 2000a, Englund et al. 2008, Outeiro et al. 2008). This phenomenon may not be due to a real fall in recruitment levels, since other factors such as biased sampling techniques probably result in 
significant under-estimations of juvenile abundance (al-Mousawi 1991, Hastie \& Cosgrove 2002).

It is difficult to determine whether or not the low juvenile abundance observed in many populations is entirely due to sampling bias. In other words: (1) Has there been an underlying general fall in the survival rates of young mussels in Scottish Margaritifera margaritifera populations? and (2) If the answer is yes, to what extent and when has this occurred? These questions are fundamental to the conservation of this species, and detailed investigations of recruitment levels in Scottish populations are warranted. In the short term, records of the smallest and/or youngest specimens recently found in different rivers can provide upto-date recruitment information. Annual age structure data of juvenile mussels may highlight recent trends and/or disturbances in recruitment (provided samples were large enough). In the medium to long term, however, the most useful approach would be to monitor population structures every 10 to $20 \mathrm{yr}$. An alternative, less expensive strategy would be to determine what constitutes the size/age profile of an 'ideal,' stable, functioning $M$. margaritifera population and to use this as a standard against which those of other populations could be compared (Young et al. 2001b).

The objectives of the present study were therefore (1) to investigate trends in recruitment in selected pearl mussel populations over a $20 \mathrm{yr}$ period (in 3 different time frames); (2) to determine if these processes are presently running at 'normal' sustainable levels; and (3) to identify and comment on local factors that might seriously threaten these populations.

\section{MATERIALS AND METHODS}

Surveys of mussel beds in 8 selected Scottish rivers (River A, River B, Dee, Kerry, Moidart, South Esk, Spey, Stac Burn) were carried out during 3 separate periods (1984-85, 1996-97, 2006-07). Rivers A and B are small upland streams in northwest Scotland. These differed considerably in physical character and were known to support a wide range of Margaritifera margaritifera population sizes (Table 1). The rivers were selected to represent those remaining populations in Scotland considered to be currently viable on the basis of recent surveys (Cosgrove et al. 2000). The same sites (localities) were sampled on each occasion. Each site (50 $\mathrm{m}$ stretch) was photographed and mapped in 1984-85 (al-Mousawi 1991), allowing precise relocation during subsequent visits. We surveyed 2 to 3 sites (100 to $\left.150 \mathrm{~m}^{2}\right)$ in each river. Owing to the present threat of illegal pearl fishing, Rivers A and B (small streams in northwest Scotland considered to be highly vulnerable) were code-lettered, and no specific site
Table 1. Margaritifera margaritifera. Physical characteristics of rivers surveyed and size estimates of resident populations in reach containing mussels (Hastie et al. 2000a)

\begin{tabular}{|lccc|}
\hline Location & $\begin{array}{c}\text { Length } \\
(\mathrm{km})\end{array}$ & $\begin{array}{c}\text { Width } \\
(\mathrm{m})\end{array}$ & $\begin{array}{c}\text { Population } \\
\left(\times 10^{6} \text { mussels }\right)\end{array}$ \\
\hline River A & 4 & 2 & $<0.1$ \\
River B & 2 & 1 & $<0.1$ \\
Dee & 80 & 50 & $\sim 1.5$ \\
Kerry & 4 & 15 & $\sim 1.0$ \\
Moidart & 4 & 15 & $\sim 0.4$ \\
South Esk & 80 & 35 & $\sim 2.5$ \\
Spey & 150 & 50 & $\sim 10.0$ \\
Stac Burn & 3 & 2 & $<0.1$ \\
\hline
\end{tabular}

details and map references are disclosed here in order to maintain confidentiality.

At each site, along $50 \mathrm{~m}$ transects, $1 \mathrm{~m}^{2}$ metal quadrat frames were thrown in at 5 to $10 \mathrm{~m}$ intervals, and all the mussels found in these were collected. After removing all the visible mussels within a quadrat, a period of 10 to 15 min was spent carefully removing the stones and weed cover and sifting the fine sediments by hand. All the mussels were then aged using standard age-calibration curves (Hendelberg 1961).

Non-destructive samples of mussels were removed from each site during the surveys (quadrat searches). Shell length ( $L$; to the nearest $\mathrm{mm}$ ) and shell ligament

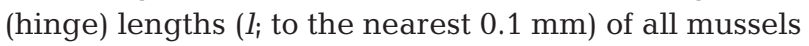
found in quadrats were measured using dial callipers. The mussels were then carefully returned to the riverbed.

Size-stratified samples of 30 to 100 mussel shells were taken from each site for age determination. The taking of live specimens was avoided whenever possible. For example, many recently dead mussels (flood and fishing mortalities) were found at each site. Estimated total lengths and uneroded section lengths of individual shell ligaments were measured externally. The ligaments were then carefully cut with a razor blade, and the numbers of annual growth lines (annuli) in these were counted using a low power stereo microscope $(10 \times)$.

Age calibration curves for each population were calculated using a standard technique developed for Margaritifera margaritifera (Hendelberg 1961). This involved the construction of a calibration curve for each population, by plotting shell ligament length estimates against corresponding age estimates (Hastie et al. 2000a). A sample ( $\mathrm{n}=10$ to 60 ) of juvenile mussel shells $(L<65 \mathrm{~mm})$ with intact ligaments was taken in order to provide estimates of the ages represented by the missing (eroded) ligament section lengths of older shells. These were aged by counting the number of external shell lines by eye and by comparing them 
with counts of the number of ligament lines. Total ligament length estimates were then plotted against age estimates, and the lines of best fit for all aged shells were estimated by regression analyses. The fitted line equations were used to estimate the number of annuli in the missing ligament sections in older, eroded shells so that these could be aged completely. Calibration curves were then calculated by fitting standard logistic curves to the ligament length-at-age data, and full age distributions were produced from mussel shell ligament length data obtained from each site (Table 2).

During within-river investigations (Hastie et al. 2000a), large (pooled) samples of mussels aged 1 to $10 \mathrm{yr}$ were obtained from 2 rivers (Kerry, South Esk). Based on these, age-frequency profiles were constructed.

Preliminary mussel density estimates were also obtained for each river, during 1996-97 and 2006-07. Riverbed searches of mussel beds were carried out using a standard protocol (Young et al. 2001c). Total counts of visible mussels within $1 \times 50 \mathrm{~m}$ transects (carried out at least $1 \mathrm{~m}$ in from either river bank) were recorded with the aid of a glass-bottomed viewer.

\section{RESULTS}

\section{Signs of recent recruitment}

Mussels aged $<5$ yr ( $L$ generally $<30 \mathrm{~mm}$ ) were found at all sites during 2006-07, indicating that at least some recruitment had recently occurred in these populations. However, small mussels were generally quite difficult to find. The observed juvenile ( 1 to $10 \mathrm{yr}$ ) age-frequency distributions of the Rivers Kerry and South Esk Margaritifera margaritifera populations in 1996-97 (Figs. 1 \& 2, respectively) are generally similar. Two main features, common to both are (1) considerable within-river variation, indicating different lev-

Table 2. Margaritifera margaritifera. Mussel age-shell ligament length calibration curves for age estimations. Logistic parameters are determined by the fitted equation, $L_{t}=a \ln (t)+$ $b$, where $L_{t}=$ shell ligament length at age $t, a=$ slope, $b=$ intersect, $\mathrm{r}^{2}=$ correlation coefficient

\begin{tabular}{|lcccc|}
\hline Location & Sample (n) & $a$ & $b$ & $\mathrm{r}^{2}$ \\
\hline River A & 37 & 18.167 & -17.788 & 0.964 \\
River B & 52 & 15.148 & -23.367 & 0.917 \\
Dee & 68 & 21.155 & -25.837 & 0.908 \\
Kerry & 93 & 18.822 & -24.070 & 0.959 \\
Moidart & 82 & 19.179 & -21.697 & 0.893 \\
South Esk & 65 & 19.252 & -24.467 & 0.904 \\
Spey & 81 & 16.771 & -14.724 & 0.902 \\
Stac Burn & 31 & 17.327 & -21.412 & 0.956 \\
\hline
\end{tabular}
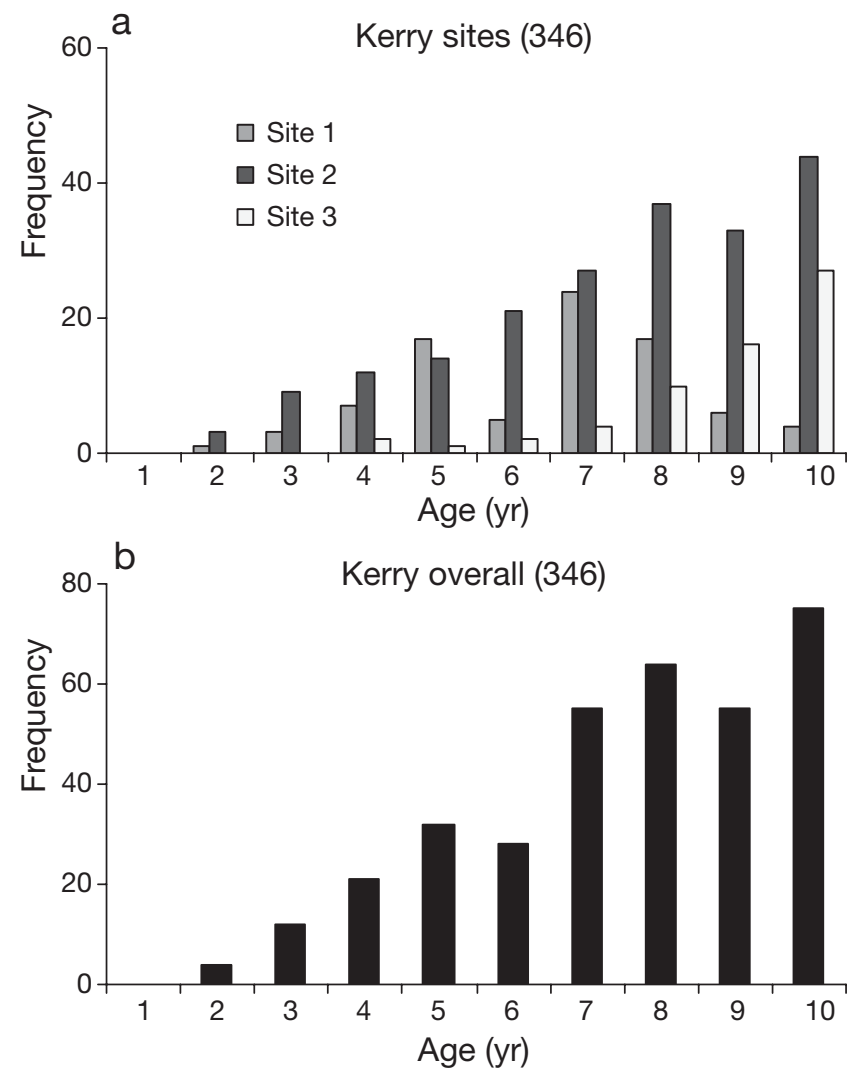

Fig. 1. Margaritifera margaritifera. Age-frequency histograms of juvenile mussels observed in the River Kerry in 1996 for (a) different sites and (b) the entire river. Total sample sizes in parentheses

els of recruitment at different sites; and (2) positive trends between mussel age and observed overall abundance in these rivers. In the River Kerry, most of the recruitment appears to be occurring at Site 2, which represents the middle reach of the river, with variable numbers of young mussels present elsewhere (Fig. 1a). Except for slightly fewer than expected 6 yr old and $9 \mathrm{yr}$ old mussels, the trend between age and overall abundance in the pooled sample is steady (Fig. 1b). In the River South Esk, relatively low numbers of young mussels were found at Site 1, the uppermost site. Again, the pooled age-abundance trend is steady, except for slightly more than expected 5 to $6 \mathrm{yr}$ olds (Fig. 2b).

\section{Population structure}

The overall ranges in age and size, observed in 1996-97 and 2006-07 were generally similar, with a few exceptions (Table 3). For example, maximum sizes observed were notably smaller (by $>10 \mathrm{~mm}$ ) in 2006-07 in the Rivers Dee and South Esk. Differences 

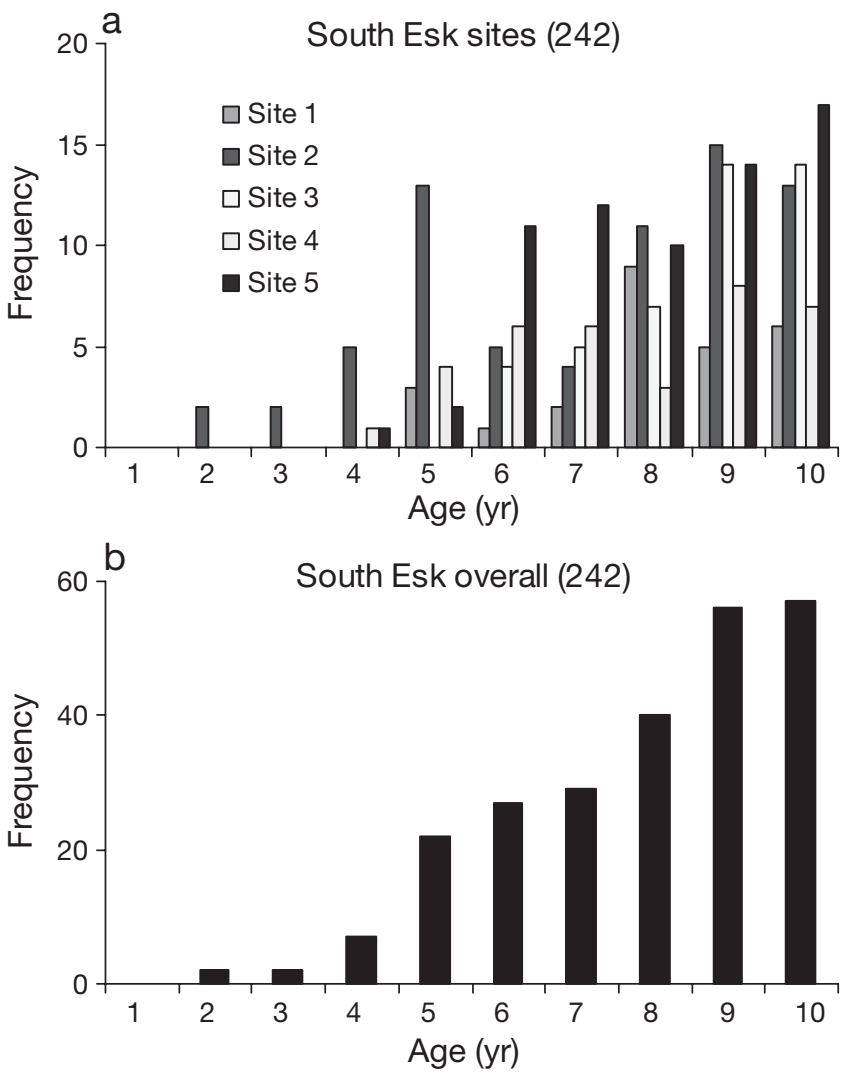

Fig. 2. Margaritifera margaritifera. Age-frequency histograms of juvenile mussels observed in the River South Esk in 1997 for (a) different sites and (b) the entire river. Total sample sizes in parentheses

Table 3. Margaritifera margaritifera. Absolute length and age ranges (min.-max. values) of mussels found in rivers during the periods 1996-97 and 2006-07

\begin{tabular}{|lcccl|}
\hline \multirow{2}{*}{ Location } & \multicolumn{2}{c}{ Length $(\mathrm{mm})$} & \multicolumn{2}{c|}{ Age (yr) } \\
& $1996-97$ & $2006-07$ & $1996-97$ & $2006-07$ \\
\hline River A & $22-119$ & $1-125$ & $4-95$ & $1-117$ \\
River B & $8-97$ & $14-99$ & $2-92$ & $6-112$ \\
Dee & $17-150$ & $10-138$ & $3-81$ & $3-81$ \\
Kerry & $6-137$ & $7-134$ & $2-139$ & $3-151$ \\
Moidart & $10-145$ & $25-137$ & $3-143$ & $6-119$ \\
South Esk & $20-134$ & $12-117$ & $5-88$ & $3-70$ \\
Spey & $9-124$ & $10-125$ & $2-88$ & $3-68$ \\
Stac & $19-126$ & $24-117$ & $5-149$ & $5-104$ \\
\hline
\end{tabular}

in maximum age estimates were also notable ( $>20 \mathrm{yr})$ in Rivers A and B (older) and Rivers Moidart, Spey, and Stac Burn (younger) in 2006-07. However, most of the differences (in min.-max. values) observed were due to 1 or 2 individual records. Size-frequency distributions observed in 8 populations during 198485, 1996-97, and 2006-07 are provided in Fig. 3. These were generally similar in each population, except for distinct differences in size modes observed in the River B, River South Esk, and Stac Burn samples. A predominance of large mussels $(L>50 \mathrm{~mm})$ was observed at all sites. Corresponding agefrequency distributions are provided in Fig. 4. There were marked differences between the observed size and age distributions. The latter indicated greater numbers of young mussels than were suggested by the former. However, as Fig. 4 shows, even in the age distributions, the expected predominance of young mussels was not achieved.

Additional quantitative information is summarised in Table 4 . Over the past $20 \mathrm{yr}$, the age ranges observed have remained generally the same at each site, except for the River B and Stac Burn (Fig. 4b \& 4h, respectively). Maximum ages recorded in each population ranged from $~ 90$ yr (South Esk, Spey) to 150 yr (Stac Burn). Recruitment levels appear to have varied considerably. In most samples we observed, the relative numbers of mussels aged 11 to $20 \mathrm{yr}$ were greater than expected, based on the numbers of mussels age 1 to $10 \mathrm{yr}$ observed in preceding decades, indicating that the 1 to $10 \mathrm{yr}$ age class may have been consistently under-sampled. Observed proportions of juvenile mussels (aged $\leq 20 \mathrm{yr}$ ) ranged from 4.9 (River $B_{;}$2007) to $75.5 \%$ (South Esk; 1984). Proportions of old mussels ( $>50 \mathrm{yr}$ ) ranged from 0.0 (Dee, South Esk, 1984) to 69.5 \% (River B, 2007).

\section{Changes in mussel density}

Mussel density estimates for each site during 1996-97 and 2006-07 are provided in Table 5. The overall numbers of mussels found at all sites fell from 11721 in $1996-97$ to 10339 in $2006-07$, a $12 \%$ decrease. Substantial changes in mussel abundance $(>5 \%)$ were observed in the Rivers Dee, Kerry, Moidart, Spey, and Stac Burn populations. These indicated marked declines in overall abundance (5 to $50 \%$ ) at these sites during the decade, except for the Spey, where a marked increase $(55 \%)$ was recorded.

\section{Detailed comparisons}

River A

The population of River A appears to have recruited extremely well, since the proportion of juvenile mussels (aged $\leq 20$ yr) increased steadily, from $12.5 \%$ in 1984 to $34.1 \%$ in 2007 (Table 4). The modal size class decreased from 101-110 mm in 1984 to $81-90 \mathrm{~mm}$ in 2007 (Fig. 3a). The modal age class decreased from 41-50 yr to 21-30 yr during the same period (Fig. 4a). No significant change in overall abundance was observed at this site between 1997 and 2007 (Table 5). 

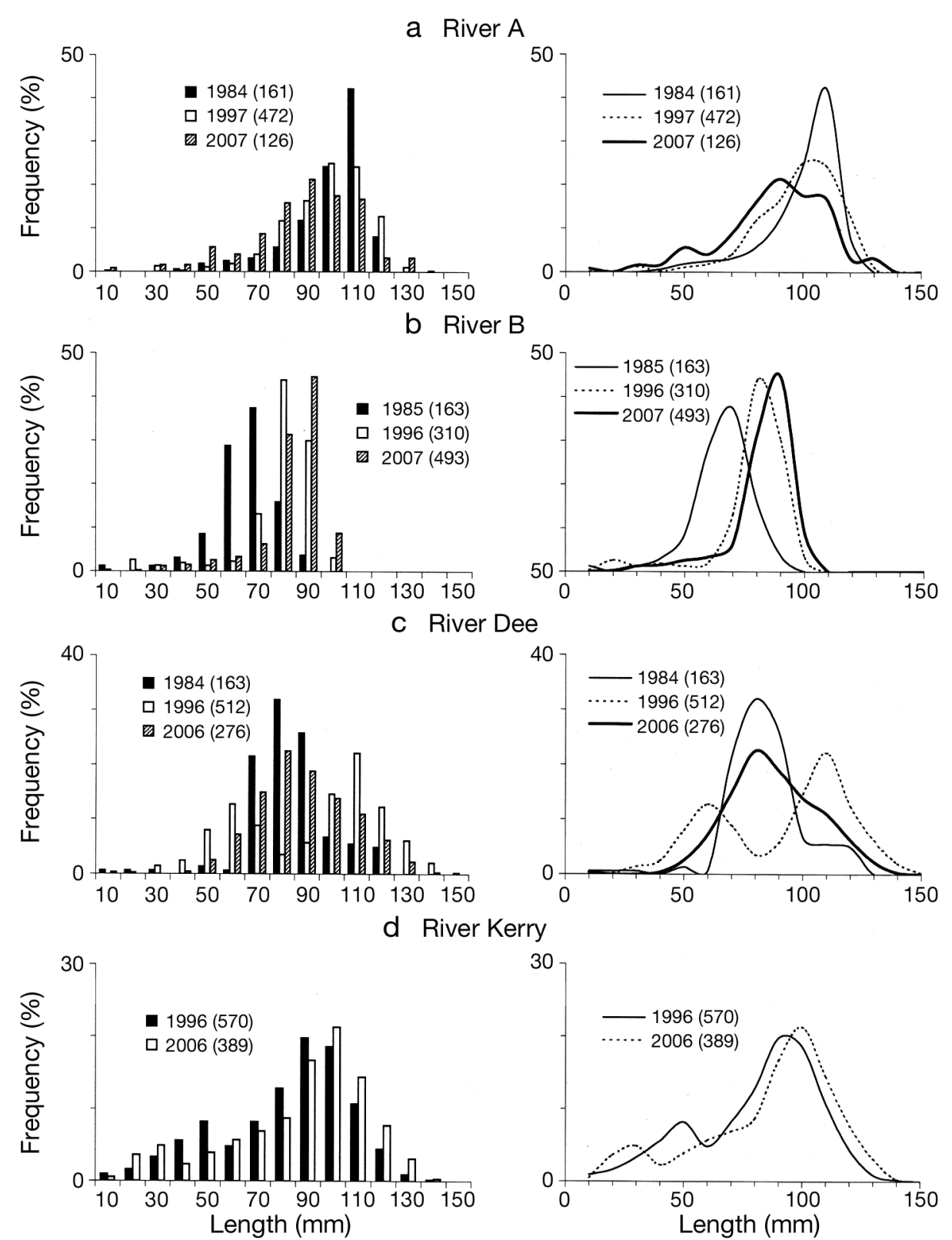

Fig. 3. (continued overleaf) Margaritifera margaritifera. Comparative length-frequency histograms and smoothed lengthfrequency distributions of 8 populations observed in 1984-85, 1996-97, and 2006-07. Lines smoothed by a cubic spline function.

Respective sample sizes in parentheses

River B

A marked, steady increase in modal size was observed in the population of River B, from $61-70 \mathrm{~mm}$ in 1985 to 81-90 mm in 2007 (Fig. 3b). The modal age class also increased, from 21-40 yr to 61-70 yr over the same period (Fig. 4b), indicating poor recent recruitment. The proportion of old mussels (aged $>50 \mathrm{yr}$ ) also increased steadily, from $9.8 \%$ in 1985 to $69.5 \%$ in 2007 (Table 4). No significant change in overall abundance was observed at this site between 1997 and 2007 (Table 5).
River Dee

The size- and age-frequency distributions observed in the population of the River Dee during 1984 and 2006 are similar (although very few mussels aged $\leq 10 \mathrm{yr}$ were found in 1984; Figs. 3c \& 4c). A modal size class of 71-80 $\mathrm{mm}$ and a modal age class of 11-20 yr were observed on both occasions. However, a different, bimodal structure was observed in 1996, with modal size classes of $51-60 \mathrm{~mm}$ and 101-110 mm, modal age classes of 1-10 yr and 21-30 yr, and a marked dip in the 

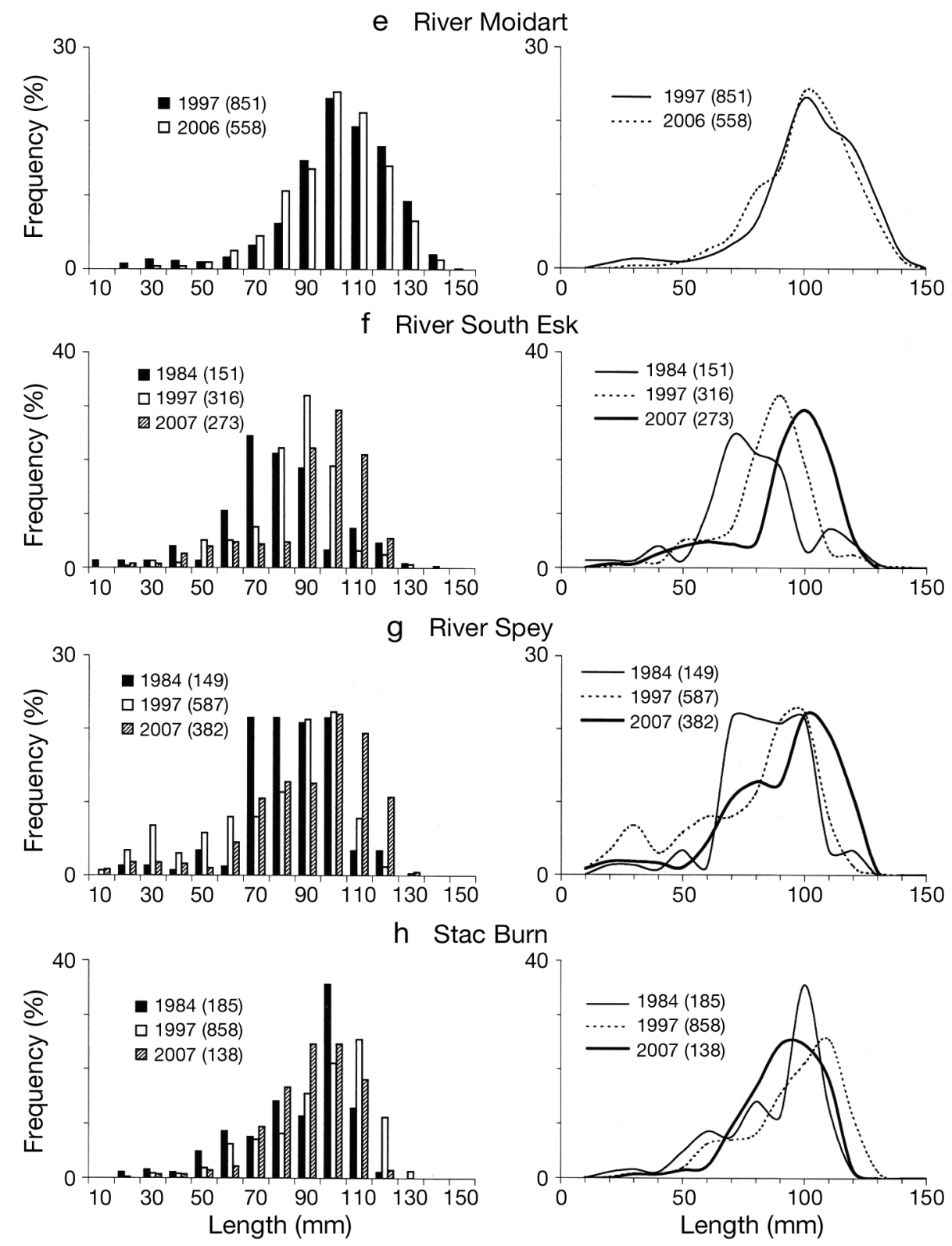

Fig. 3 (continued)

relative number of mussels aged 11 to 20 yr. A marked $(13.8 \%)$ decrease in overall abundance was recorded at this site between 1996 and 2006 (Table 5).

\section{River Kerry}

All size classes $<80 \mathrm{~mm}$, and age classes $<50$ yr were well represented in the population of the River Kerry, and modes were less clearly defined. An apparent increase in modal size was observed, from 81-90 mm in 1996 to 91-100 mm in 2006 (Fig. 3d). A slight increase in modal age was also observed, from 21-30 yr to 31-40 yr over the same period (Fig. 4d). A slight increase in the proportion of old mussels aged $>50 \mathrm{yr}$ was observed, from $17.3 \%$ in 1996 to $21.5 \%$ in 2006 (Table 4). A marked (16.9\%) decrease in overall abundance was recorded at this site between 1997 and 2006 (Table 5).

\section{River Moidart}

Between 1997 and 2006, the modal size remained unchanged in the population of the River Moidart, at 101$110 \mathrm{~mm}$ (Fig. 3e). However, a slight increase in modal age was observed in this population, from 21-30 yr in 1997 to $31-40$ yr in 2006. Relatively few mussels $\leq 10 \mathrm{yr}$ 

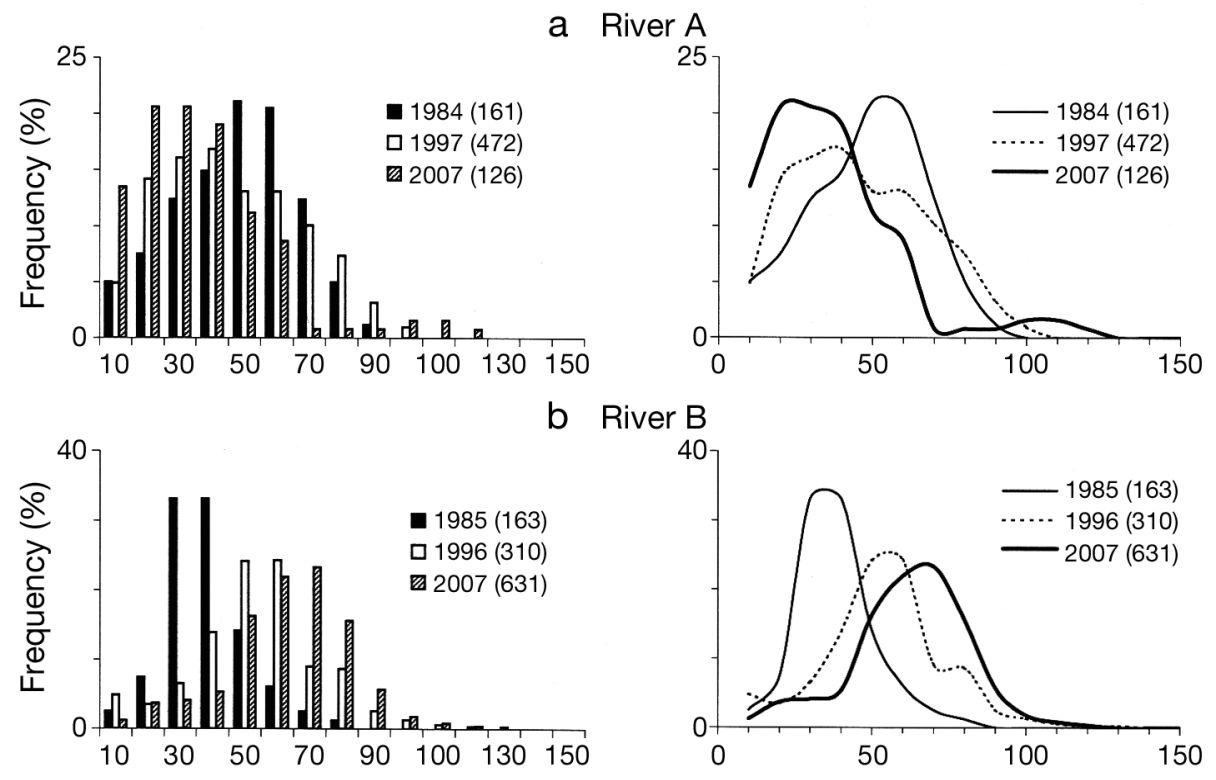

River B

C River Dee
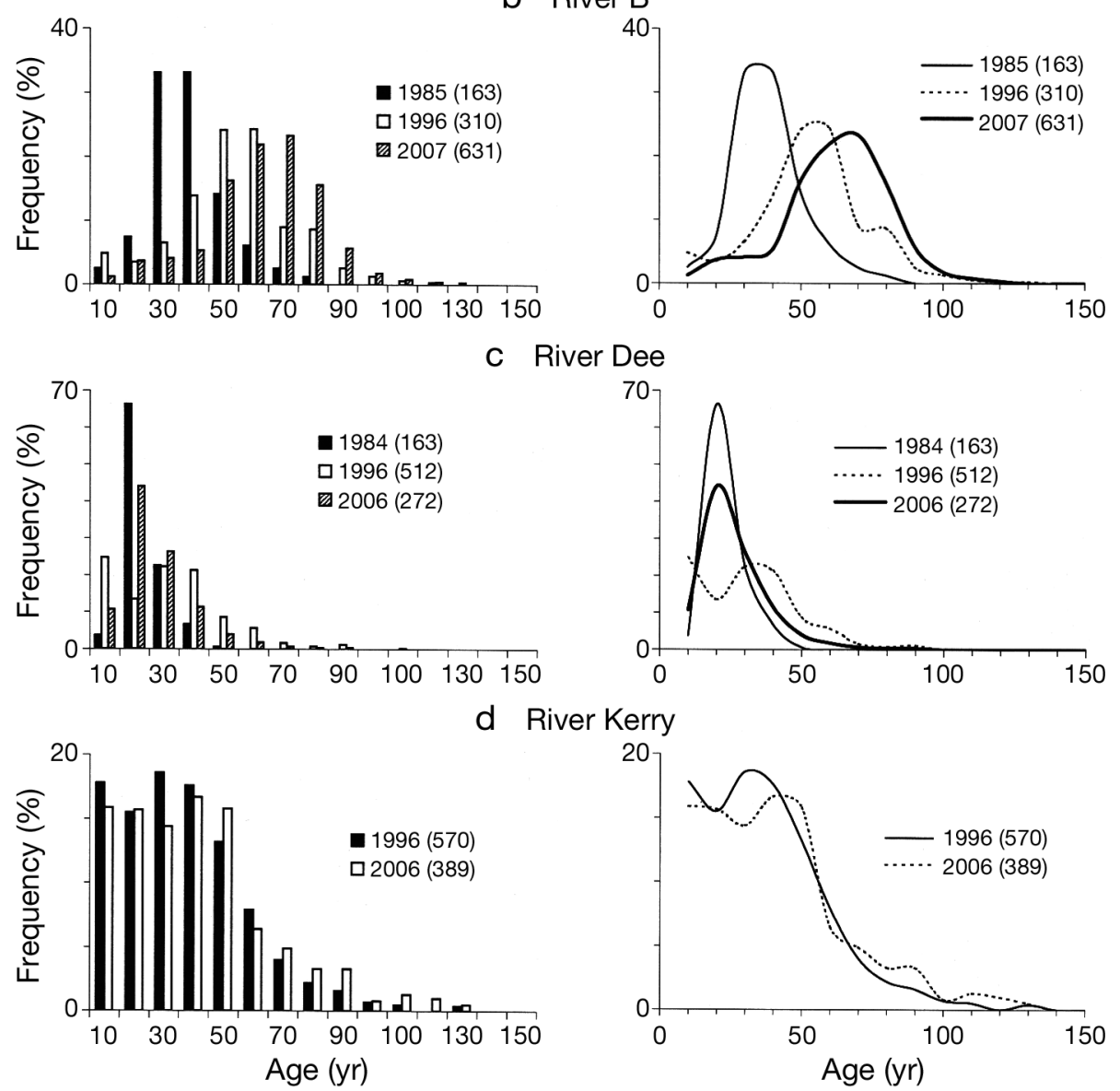

Fig. 4. (continued overleaf) Margaritifera margaritifera. Comparative age-frequency histograms and smoothed age-frequency distributions of 8 populations observed in 1984-85, 1996-97, and 2006-07. Lines smoothed by a cubic spline function. Respective sample sizes in parentheses

old $(<5 \%)$ were found on either occasion (Fig. 4e). A marked $(27.7 \%)$ decrease in overall abundance was recorded at this site between 1997 and 2006 (Table 5).

\section{River South Esk}

A marked, steady increase in modal size was observed in the population of the River South Esk, from $61-70 \mathrm{~mm}$ in 1984 to $91-100 \mathrm{~mm}$ in 2007 (Fig. 3f). The modal age also increased, from 11-20 yr to 31-40 yr during the same period (Fig. 4f). The proportion of mussels aged $\leq 20$ yr fell dramatically during the same period, from 75.5 to $21.2 \%$ (Table 4). No significant change in overall abundance was observed at this site between 1997 and 2007 (Table 5).

\section{River Spey}

The modal size increased in the population of the River Spey from $61-70 \mathrm{~mm}$ in 1984 to $91-100 \mathrm{~mm}$ in 2006 (Fig. 3g). An increase in modal age was also observed in 

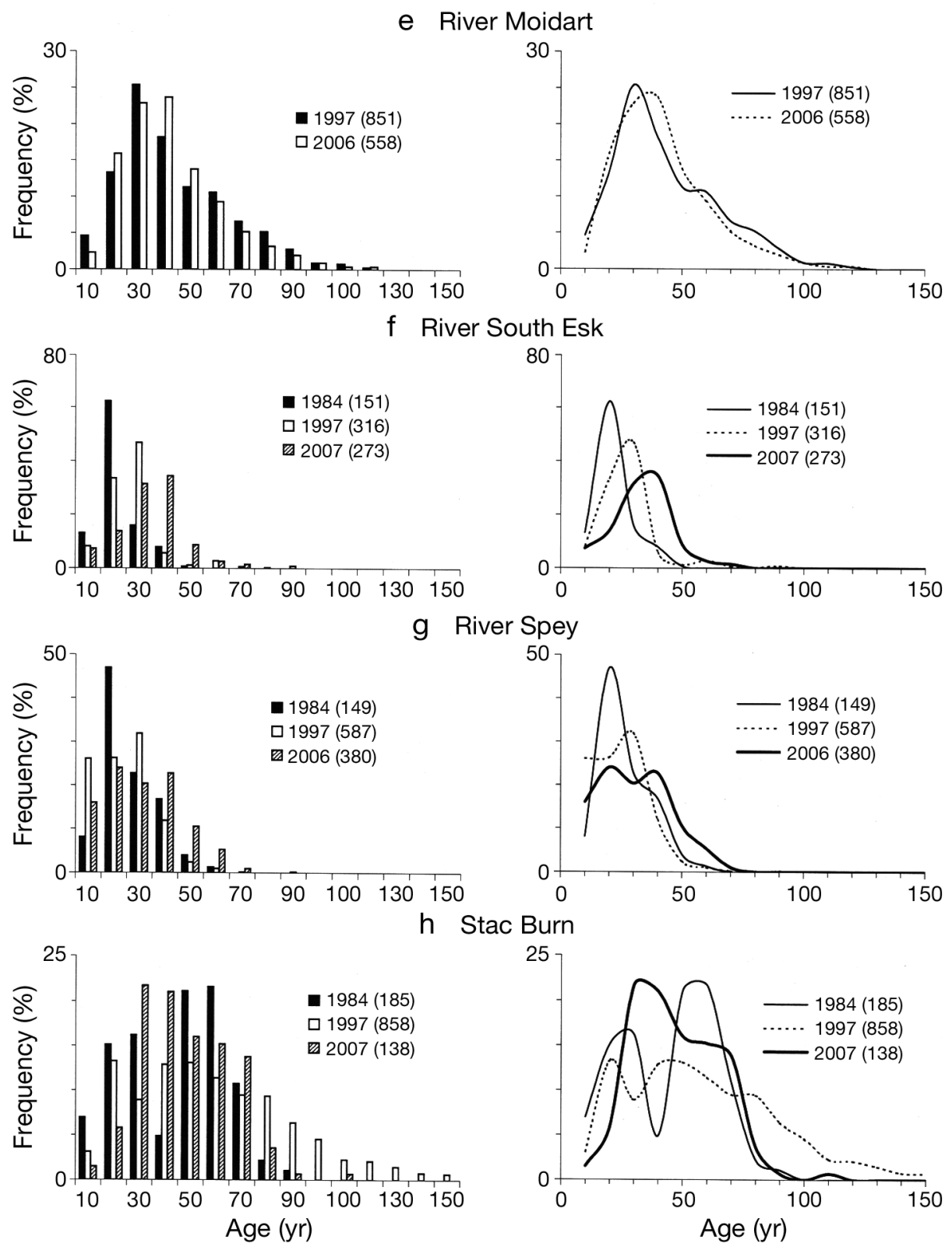

Fig. 4 (continued)

this population, from 11-20 yr to 31-40 yr over the same period (Fig. 4g). The proportion of old mussels aged $>50 \mathrm{yr}$ increased from 1.3 to $6.3 \%$ during the same period (Table 4). A marked (55.0\%) increase in overall abundance was recorded at this site between 1997 and 2006 (Table 5).

\section{Stac Burn}

The number of apparent size modes appeared to decrease gradually, from 3 in 1984, to 2 in 1997, to 1 in 2007 (Fig. 3h). The population of Stac Burn also appeared to have a complex (bi- or tri-modal) age structure. The primary modal age class increased from 41-50 yr in 1984 to $51-60 \mathrm{yr}$ in 1997. However, the modal age class in 2007 was 21-30 yr (Fig. 4h). The proportion of young mussels aged $\leq 20$ yr fell steadily, from $22.1 \%$ in 1984 to $7.3 \%$ in 2007 (Table 4). A marked (50.4\%) decrease in overall abundance was recorded at this site between 1997 and 2007 (Table 5).

\section{Potential threats}

Based on field observations and anecdotal evidence noted during this study, and the findings of recent 
Table 4. Margaritifera margaritifera. Relative abundances of young ( $\leq 20 \mathrm{yr}$ ) and old ( $>50 \mathrm{yr}$ ) mussels found in samples during 1984-85 (River B was surveyed in 1985, all others were surveyed in 1984), 1996-97 (Rivers B, Dee, and Kerry were surveyed in 1996, all others were surveyed in 1997), and 2006-07 (River A, River B, and Stac Burn were surveyed in 2007, all others were surveyed in 2006). Corresponding sample sizes provided in Fig. 3. -: no data

\begin{tabular}{|c|c|c|c|c|}
\hline \multirow[t]{2}{*}{ Location } & \multirow[t]{2}{*}{ Age (yr) } & \multicolumn{3}{|c|}{ Proportions of mussels (\%) } \\
\hline & & $1984-85$ & 1996-97 & $2006-07$ \\
\hline \multirow[t]{2}{*}{ River A } & $\leq 20$ & 12.5 & 19.1 & 34.1 \\
\hline & $>50$ & 39.1 & 33.8 & 11.1 \\
\hline \multirow[t]{2}{*}{ River B } & $\leq 20$ & 9.9 & 8.3 & 4.9 \\
\hline & $>50$ & 9.8 & 47.1 & 69.5 \\
\hline \multirow[t]{2}{*}{ Dee } & $\leq 20$ & 70.0 & 38.3 & 54.8 \\
\hline & $>50$ & 0.0 & 9.5 & 3.3 \\
\hline \multirow[t]{2}{*}{ Kerry } & $\leq 20$ & - & 33.3 & 31.6 \\
\hline & $>50$ & - & 17.3 & 21.5 \\
\hline \multirow[t]{2}{*}{ Moidart } & $\leq 20$ & - & 17.9 & 18.1 \\
\hline & $>50$ & - & 27.2 & 21.4 \\
\hline \multirow[t]{2}{*}{ South Esk } & $\leq 20$ & 75.5 & 41.7 & 21.2 \\
\hline & $>50$ & 0.0 & 4.6 & 4.1 \\
\hline \multirow[t]{2}{*}{ Spey } & $\leq 20$ & 55.1 & 52.4 & 40.0 \\
\hline & $>50$ & 1.3 & 1.4 & 6.3 \\
\hline \multirow[t]{2}{*}{ Stac Burn } & $\leq 20$ & 22.1 & 16.4 & 7.3 \\
\hline & $>50$ & 35.7 & 48.7 & 34.0 \\
\hline
\end{tabular}

surveys (Cosgrove et al. 2000, Hastie 2006), the main threats to the medium-term stability of the 8 populations under study are summarised in Table 6 . Destructive pearl fishing is considered to remain a serious threat to all 8 populations, whilst the reduction of suitable riverbed habitat, pollution incidents, and declining host fish stocks are issues in certain rivers.

\section{DISCUSSION}

\section{Recent recruitment levels}

The positive trends between age and abundance observed in the Rivers Kerry and South Esk Margaritifera margaritifera samples (Figs. 1 \& 2) indicate significant under-estimation of younger age classes in the field. This corroborates the findings of Hastie \& Cosgrove (2002), who determined size/age-specific sampling bias experimentally for this species. In the field, small, young individuals are difficult to find, even in sieved samples (Young \& Williams 1984). Comparisons of the age-frequency profiles at different Kerry and South Esk sites indicate considerable within-river variation. The relatively large numbers of juveniles found and the steady declines in 'abundance' with decreasing age observed at Kerry Site 2 (Fig. 1a) and South
Table 5. Margaritifera margaritifera. Noumber of visible mussels counted in 50 m transects during 1996-97 (Rivers B, Dee, and Kerry were surveyed in 1996, all others were surveyed in 1997) and 2006-07 (River A, River B, and Stac Burn were surveyed in 2007, all others were surveyed in 2006). Exact locations of transects are confidential because of threat of illegal pearl fishing

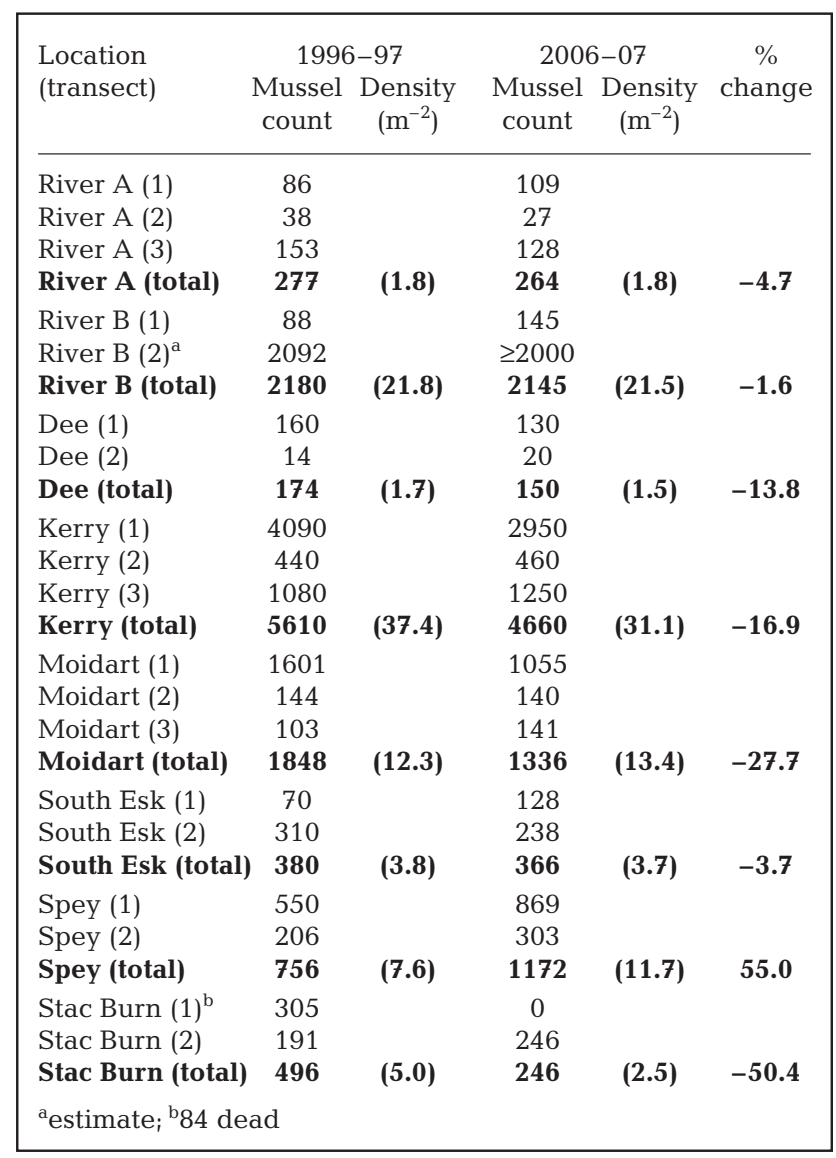

Table 6. Margaritifera margaritifera. Potential threats to the conservation status of resident populations in the 8 rivers surveyed based on field observations, anecdotal evidence, and previous surveys (Cosgrove et al. 2000, Hastie 2006). $\mathrm{PF}=$ pearl fishing, $\mathrm{HL}=$ loss of riverbed habitat, $\mathrm{PO}=$ pollution, $\mathrm{HF}=$ decline in host fish stocks

\begin{tabular}{|c|c|c|c|c|}
\hline \multirow{2}{*}{ Location } & \multicolumn{4}{|c|}{ - Main threat } \\
\hline & $\mathrm{PF}$ & HL & $\mathrm{PO}$ & $\mathrm{HF}$ \\
\hline River A & - & & & \\
\hline River B & - & - & & - \\
\hline Dee & - & & & \\
\hline Kerry & • & & & \\
\hline Moidart & - & - & & \\
\hline South Esk & - & - & - & \\
\hline Spey & • & & & \\
\hline Stac Burn & - & & - & \\
\hline
\end{tabular}

Esk Site 5 (Fig. 2a) suggest that relatively high levels of recruitment have occurred at these sites. By contrast, recruitment levels at other sites have been lower and 
more variable (e.g. Kerry Site 1, South Esk Site 2). Low numbers of juveniles may reflect naturally less-stable riverbed habitat, or even lower (perhaps critical) host fish densities at these sites (Osterling et al. 2008). However, since relatively small numbers of juveniles were found at some sites, the possible effects of greater sampling error should also be considered.

Whatever the reasons are for this observed withinriver variability, it is quite clear that historical comparisons of Margaritifera margaritifera populations should be site-specific, particularly when sample sizes are small ( $\mathrm{n}<1000$ mussels). Pooling samples appeared to 'smooth' the age-frequency distributions of both rivers (Figs. 1b \& 2b), thus it may be possible to compare whole river samples (provided these are large enough). Further research on this topic would be worthwhile.

\section{Population structure}

The marked differences between the size and age distributions are mainly due to non-linear growth patterns. Juvenile Margaritifera margaritifera grow very rapidly compared to adults, typically reaching half maximum size $(L)$ in $<15$ yr (Hastie et al. 2000a). Therefore, some of the smaller size classes in a sizefrequency histogram may only contain a proportion of young mussels at any given age, whereas each of the larger size classes will almost certainly include older mussels drawn from a wide age range. Hence, 'sizeonly' distributions tend to greatly exaggerate the predominance of 'older' mussels in a population. Nevertheless, even in the age distributions, there is an apparent lack of young mussels $(<10 \mathrm{yr})$, except perhaps for the River Kerry sample. However, the 'appearance' of more 11 to $20 \mathrm{yr}$ olds than expected in samples in 1996-97 and 2006-07 provides evidence that the 1-10 yr class was consistently under-estimated in 1984-85 and 1996-97. This age class may be undersampled by $>50 \%$ in some populations (Hastie \& Cosgrove 2002). Although adult and juvenile M. margaritifera are generally found in similar areas of riverbed, the latter have more specific habitat requirements and tend to be more aggregated in distribution (Hastie et al. 2000b). Consequently, sampling error is far greater for juvenile $M$. margaritifera, and they are easily missed during riverbed searches (Hastie \& Cosgrove 2002).

Recruitment levels in the different populations varied considerably, however, and age-specific sampling bias cannot fully explain the apparent lack of juvenile mussels in some populations. Comparisons of the 1984-85, 1996-97, and 2006-07 age-frequency distributions are discussed in detail (site-by-site) below.

\section{Changes in mussel density}

The differences in mussel density observed at certain sites between 1996-97 and 2006-07 suggest that significant changes in overall abundance may have occurred. These varied considerably between different rivers, and no general trend was apparent. However, the $12 \%$ drop in overall numbers of mussels found at all sites is of some concern. Some of the differences observed may have been associated with sampling error, although it was not possible to compute statistical confidence limits for density estimates due to small sample size (2 to 3 transects per site; Table 5). Nevertheless, it was apparent that significant changes in abundance had occurred at some sites, particularly in the River Spey and Stac Burn, where obvious changes in mussel density (>50\%) were observed (Table 5).

\section{Detailed comparisons}

\section{River A}

The high, increasing proportion of juvenile mussels observed in the population of the River A indicate that recruitment levels have been at least stable, possibly increasing during the past 2 decades (Fig. 3a). However, the continued, backward shift in modal age class, from $41-50 \mathrm{yr}$ in 1984 to $21-30 \mathrm{yr}$ in 2007, suggests that a significant loss of older mussels occurred during this period. This may be due to the removal of large mussels by pearl fishers. River A is a remote, fairly inaccessible site, and al-Mousawi (1991) considered the resident Margaritifera margaritifera population to be unexploited. However, signs of destructive pearl fishing (scattered broken shells along the length of the river) were later reported by Cosgrove \& Young (1998). Although no signs of pearl fishing activity have been reported at this site since the complete ban in 1998, it is still considered to be a significant threat.

\section{River B}

The shift in modal age class, from 21-40 yr in 1985 to 61-70 yr in 2007 (Fig. 3b), is a clear indication that the population of the River B is gradually ageing. Based on the small, decreasing numbers of mussels aged $\leq 20 \mathrm{yr}$ found (Table 1), it appears that some recruitment continues (albeit at historically low levels). This appears to be a common feature of Margaritifera margaritifera populations in small streams, which may be linked to recent climatic changes (Hastie et al. 2003) and/or the decline of host salmonid stocks in northwest Scotland (Hastie \& Cosgrove 2001). Alternatively, it may be that 
major recruitment events in these populations only naturally occur years or even decades apart. This could perhaps be investigated by higher resolution of the age distribution, involving very large samples of mussels ( $\mathrm{n}>1000$ ) and more accurate age estimations (yearly intervals). At present, this population does not appear to be recruiting at sustainable levels. Since the mussel bed at this particular site is particularly dense (>20 mussels $\mathrm{m}^{-2}$ overall; Table 5), perhaps less riverbed habitat for settlement of mussel seed is currently available, resulting in reduced post-settlement survival and low recruitment levels.

\section{River Dee}

The (bimodal) age structure observed in 1996 in the population of the River Dee differed markedly from those in 1984 and 2006. Their modal age classes, however, may be closely linked. For example, the 11-20 yr mode in 1984 appears to have progressed to 21-30 yr in 1996. Similarly, the 1-10 yr mode in 1996 may be linked to the 11-20 yr mode in 2006, thereby accounting for observed differences in age structure (Fig. 3c). The riverbed at this particular site has been historically disturbed by river engineering works (bank reinforcements). Since this activity can impact mussel beds (Cosgrove \& Hastie 2001), this may explain the recent decrease in mussel density observed in this population (Table 5). It may also have resulted in intermittent recruitment patterns, as recovering areas of riverbed have been re-colonised during the past 20 yr.

\section{River Kerry}

The high proportions of juvenile mussels found both in 1996 and 2006 indicate that the population of the River Kerry continues to recruit at exceptionally high levels. A slight shift in modal age class observed, from $21-30$ yr in 1996 to $31-40$ yr in 2006, may be due to the ban on pearl fishing in 1998, resulting in reduced mortality in older mussels (Hastie 2006). The observed decrease in mussel density (Table 5) may be linked to a 100 yr return flood of the River Kerry in 1998, an event that destroyed 5 to $10 \%$ of the entire Margaritifera margaritifera population (Hastie et al. 2001).

\section{River Moidart}

Although the population of the River Moidart continued to recruit, only small proportions $(<5 \%)$ of mussels aged 1 to $10 \mathrm{yr}$ were recorded in 1997 and 2006
(Table 4), indicating low recruitment levels, unlikely to sustain population size in the long term (Fig. 3e). Although it is particularly difficult to find juvenile mussels in this river, the exceptionally low numbers of mussels aged 1 to 10 yr found in 2006 cannot be fully explained by sampling bias. Unusually dense algal growth and associated siltation of the riverbed have been observed in the River Moidart during the past decade. These processes are detrimental to juvenile Margaritifera margaritifera (Hastie et al. 2000b), and therefore degradation of the riverbed habitat may have resulted in historically low recruitment levels. The observed decrease in mussel density (Table 5) may be associated with a 50 yr return flood that occurred in 2002 , when 2 to $5 \%$ of the population was destroyed (authors' pers. obs.).

\section{River South Esk}

The gradual shift in modal age class observed, from 11-20 yr in 1984 to 31-40 yr in 2007 (Fig. 3f) in the population of the River South Esk indicates that the Margaritifera margaritifera population at this particular site is ageing. Although large numbers of juveniles have been found elsewhere in this river (Fig. 2), the proportion of mussels aged $\leq 20 \mathrm{yr}$ decreased from $75 \%$ in 1984 to $21 \%$ in 2007 (Table 4). Therefore, it appears that the population at this site may have localised recruitment problems. This reach of South Esk runs through intensively cultivated farmland and there are clear signs of eutrophication, probably associated with agricultural run-off. It is also possible that pollution associated with the extensive use of herbicides and pesticides in this catchment may have affected recruitment levels. Overall recruitment levels are quite high at other sites, but given the sensitivity of juvenile $M$. margaritifera to subtle changes in water quality (Bauer 1988), this potential threat should be taken seriously.

\section{River Spey}

The large proportions of juveniles recorded in the population of the River Spey during the past 20 yr indicate high recruitment levels. The proportions of mussels aged $\leq 20$ yr decreased from $55 \%$ in 1984 to $40 \%$ in 2006 . However, this has coincided with a gradual spreading out of the age-frequency distribution (Fig. $3 \mathrm{~g}$ ), probably as a result of increased survival of older mussels (aged >50 yr). This Margaritifera margaritifera population was intensively exploited prior to a pearl fishing ban in 1998 (Hastie et al. 2000a). Since then, fishing mortality has been reduced by $>90 \%$ (Hastie 2006). The observed changes in population 
structure and increase in mussel abundance observed at this site during the past $10 \mathrm{yr}$ may therefore be due to reduced fishing mortality.

\section{Stac Burn}

The marked (50\%) decrease in overall mussel abundance and the steady decrease in relative numbers of juvenile mussels observed in the population of Stac Burn during the period 1984 to 2007 indicates that this population is seriously threatened. Although periods of low recruitment are suggested in the 3 samples, the age-frequency distributions appear to be out of phase (Fig. 3h) and are difficult to interpret. Approximately 10 to $15 \mathrm{yr}$ ago, a large proportion of the Stac Burn (lowermiddle reach) mussels were suddenly wiped out, probably by poisoning (Cosgrove \& Young 1998). In 1997 there were signs that the middle reaches of Stac Burn were being re-colonised, mainly by adult mussels from the (unaffected) upper reaches. In 2007, however, there were signs that further disturbances had occurred. At present, the cause of high mortality in the Stac Burn population is unknown (investigations by Scottish Natural Heritage, Scottish Environment Protection Agency, and the University of Aberdeen are currently underway). The future conservation status of this Margaritifera margaritifera population is uncertain.

\section{Implications for conservation}

The present study demonstrates the importance of monitoring populations of endangered species over extended, ecologically relevant periods. This is particularly the case for long-lived, slow-growing species such as Margaritifera margaritifera. Juvenile mussels are highly sensitive to riverbed conditions (Buddensiek 1995), and early post-settlement survival rates may affect long-term recruitment success, whilst the adult population appears unaffected for decades. Since adult M. margaritifera may continue to reproduce for $80 \mathrm{yr}$ (Bauer 1992), significant reductions in recruitment are often difficult to detect in the short term ( $<10 \mathrm{yr})$. Furthermore, very small mussels are very difficult to find in the field, and consequently negative search results for juveniles are often unreliable (Hastie \& Cosgrove 2002). Comparing M. margaritifera population size and/or age distributions over decades is considered to be a worthwhile conservation management strategy. As a result of the recent listing of $M$. margaritifera as a qualifying interest in the designation of a number of 'Special Areas for Conservation' (SACs), under the European Habitats Directive (92/43/EEC), monitoring regimes (repeat surveys) are now established for sev- eral important M. margaritifera populations across Europe. This provides an excellent opportunity to study trends in other M. margaritifera populations in future.

Destructive pearl fishing remains a serious general threat to $>90 \%$ of remaining Scottish Margaritifera margaritifera populations (Cosgrove et al. 2000, Hastie 2006), and it is important for this illegal activity to be minimised by rigorous legal enforcement. Loss of riverbed habitat, possibly associated with climate change (Hastie et al. 2003), river engineering activity (Cosgrove \& Hastie, 2001), pollution events (Bauer 1988), and declining host fish stocks (Hastie \& Cosgrove 2001) are other potential threats to the conservation status of $M$. margaritifera in several rivers in Scotland and elsewhere.

\section{CONCLUSIONS}

Based on the results of this study, it appears that 4 of the Scottish Margaritifera margaritifera populations investigated (River A, Dee, Kerry, and Spey) produced sufficiently large numbers of juvenile mussels during a $20 \mathrm{yr}$ period to suggest long-term stability at these sites. Disturbance of the riverbed by engineering works and the effects of a major flood may explain the significant reductions in overall mussel density observed in the River Dee and River Kerry, respectively. An increase in mussel density in the River Spey may be a result of reduced fishing mortality following the complete ban of pearl fishing in 1998. The other 4 populations studied (Rivers B, Moidart, South Esk, and Stac Burn) did not appear to recruit sufficiently at these sites for long-term stability. The River South Esk M. margaritifera population is very large, and higher levels of recruitment were observed at other sites. The condition of the mussel beds surveyed may reflect localised conditions and cannot be considered to represent the entire South Esk population. The River B, Moidart, and Stac Burn populations are much smaller, however, and these may be currently recruiting at historically low levels. The Stac Burn population was recently affected by a major catastrophic event (probably poisoning) and may take several decades to settle. Continued monitoring of these sites every decade will provide valuable information about the long-term ecology, recovery, and dynamics of threatened $M$. margaritifera populations.

Acknowledgements. This work was supported by grants from the National Environment Research Council (NERC) and Scottish Natural Heritage (SNH). We are grateful to Phil Boon and Peter Cosgrove for their help and advice, and also to the riparian land owners for kindly granting access permission to the selected sites on each river. Jane Pool (University of 
Aberdeen) provided much appreciated technical support. Three anonymous referees kindly agreed to review the manuscript.

\section{LITERATURE CITED}

al-Mousawi B (1991) The development of ageing methods for the freshwater pearl mussel Margaritifera margaritifera (Linn.) and the population structure of exploited and unexploited populations. PhD thesis, University of Aberdeen

Bauer G (1983) Age structure, age specific mortality rates and population trend of the freshwater pearl mussel (Margaritifera margaritifera) in North Bavaria. Arch Hydrobiol 98: $523-532$

Bauer G (1986) The status of the freshwater pearl mussel Margaritifera margaritifera L. in the south of its European range. Biol Conserv 38:1-9

Bauer G (1988) Threats to the freshwater pearl mussel, Margaritifera margaritifera in central Europe. Biol Conserv 45: 239-253

Bauer G (1992) Variation in the life span and size of the freshwater pearl mussel. J Anim Ecol 61:425-436

Buddensiek V (1995) The culture of juvenile freshwater pearl mussels Margaritifera margaritifera in cages: a contribution to conservation programmes and the knowledge of habitat requirements. Biol Conserv 74:33-44

Cosgrove PJ, Hastie LC (2001) Conservation of threatened freshwater pearl mussels: river management, translocation and conflict resolution. Biol Conserv 99:183-190

Cosgrove PJ, Young MR (1998) The status of the freshwater pearl mussel M. margaritifera (L.) in Scotland. Confidential report to Scottish Natural Heritage (SNH), Edinburgh

Cosgrove PJ, Young MR, Hastie LC, Gaywood M, Boon PJ (2000) The status of the freshwater pearl mussel Margaritifera margaritifera (L.) in Scotland. Aquat Conserv Mar Freshw Ecosyst 10:197-208

Englund D, Brunberg A, Jacks G (2008) A case study of a freshwater pearl mussel (Margaritifera margaritifera) population in central Sweden. Geogr Ann Ser A Phys Geogr 90:251-258

Hastie LC (2006) Determination of mortality in exploited freshwater pearl mussel (Margaritifera margaritifera) populations. Fish Res 80:305-311

Hastie LC, Cosgrove PJ (2001) The decline of migratory salmonids: a new threat to pearl mussels in Scotland. Freshw Forum 15:85-96

Hastie LC, Cosgrove PJ (2002) Intensive searching for mussels in a fast-flowing river: an estimation of sampling bias. J Conchol 37:309-316

Hastie LC, Young MR, Boon PJ, Cosgrove PJ, Henninger B (2000a) Sizes, densities and age structures of Scottish Margaritifera margaritifera (L.) populations. Aquat Conserv Mar Freshw Ecosyst 10:229-247

Hastie LC, Boon PJ, Young MR (2000b) Physical microhabitat

Editorial responsibility: William Wallace,

Staten Island, New York, USA requirements of freshwater pearl mussels, Margaritifera margaritifera (L.). Hydrobiologia 429:59-71

Hastie LC, Boon PJ, Young MR, Way S (2001) The effects of a major flood on an endangered freshwater mussel population. Biol Conserv 98:107-115

Hastie LC, Cosgrove PJ, Ellis N, Gaywood MJ (2003) The threat of climate change to freshwater pearl mussel populations. Ambio 32:40-46

Hendelberg J (1961) The freshwater pearl mussel Margaritifera margaritifera (L.). Rep Inst Freshw Res Drottingholm 41:149-171

IUCN (International Union for the Conservation of Nature) (1991) Invertebrate red list. IUCN, Gland

Mackie TG, Roberts D (1992) Population characteristics of Margaritifera margaritifera in Northern Ireland. In: Proc 11th Malacological Congress, Siena. Backhuys Publishers, Oegstgeest-Leiden, p 163-169

Moog O, Nesemann RE, Ofenboeck T, Stundner C (1993) Grundlagen zum Schutz der Flussperlmuschel in Österreich. Bristol-Stiftung Forschungsstelle für Natur und Umweltschutz, Schaan

Osterling M, Greenberg LA, Arvidson BL (2008) Relationship of biotic and abiotic factors to recruitment patterns in Margaritifera margaritifera. Biol Conserv 141:1365-1370

Outeiro A, Ondina P, Fernandez C, Amaro R, Miguel ES (2008) Population density and age structure of the freshwater pearl mussel, Margaritifera margaritifera, in two Iberian rivers. Freshw Biol 53:485-496

Ross ED (1982) Studies on the biology of freshwater mussels (Lamellibranchia: Unionacea) in Ireland. MSc thesis, University College, Galway

Stober QJ (1972) Distribution and age of Margaritifera margaritifera (L.) in a Madison River (Montana, USA) mussel bed. Malacologia 11:343-350

Young MR, Williams JC (1984) The reproductive biology of the freshwater pearl mussel Margaritifera margaritifera (Linn.) in Scotland I. Field studies. Arch Hydrobiol 99: 405-422

Young MR, Cosgrove PJ, Hastie LC (2001a) The extent of, and causes for, the decline of a highly threatened naiad: Margaritifera margaritifera. In: Bauer G, Wachtler K (eds) Ecological studies, Vol 145. Ecology and evolutionary biology of the freshwater mussels Unionoidea. Springer Verlag, Berlin, p 337-357

Young MR, Hastie LC, al-Mousawi B (2001b) What represents an 'ideal' population profile for Margaritifera margaritifera? In: Anon (ed) The freshwater pearl mussel in Europe: population status and conservation strategies. Congress Report, Freiburg, p 35-44

> Young MR, Cosgrove PJ, Hastie LC, Henninger B (2001c) A standardised method for assessing the status of freshwater mussels in shallow rivers. J Mollusc Stud 67:395-396

Ziuganov V, Zotin A, Nezlin L, Tretiakov V (1994) The freshwater pearl mussels and their relationships with salmonid fish. VNIRO Russ Fed Res Instit Fish Oceanog, Moscow

Submitted: September 22, 2009; Accepted: December 4, 2009 Proofs received from author(s): March 1, 2010 